\title{
Contato fílmico: \\ relações táteis no cinema argentino contemporâneo
}

\author{
Film Contact: \\ Tactile Relations in Contemporary Argentine Cinema
}

\author{
Contacto cinematográfico: \\ relaciones táctiles en el cine argentino contemporâneo
}

Leonardo Ribeiro (Universidade Federal do Espírito Santo, Brasil) *

https://doi.org/10.22409/poiesis.v21i35.38679

\begin{abstract}
RESUMO: Este trabalho tem como objetivo investigar como as imagens cinematográficas reverberam no corpo, as tentativas de definir suas medidas e seus limites no contato entre o filme e o espectador promovido pela experiência cinematográfica. A capacidade do filme de tocar, emular as sensações em nosso corpo revela como ele também é um ser perceptivo e expressivo, com capacidade de movimento e tatilidade. E, a partir disso, procurar essas experiências corporais no cinema argentino recente, com comentários sobre os filmes Jauja e $O$ auge do humano (El auge del humano).

PALAVRAS-CHAVE: cinema; sensorialidade; corpo; Lisandro Alonso; Eduardo Williams

\footnotetext{
* Leonardo Ribeiro é mestre em Artes pelo Programa de Pós-Graduação em Artes (PPGA), bacharel em Comunicação Social, Jornalismo, e pesquisador no grupo de pesquisa Comunicação, Imagem e Afeto da Universidade Federal do Espírito Santo. E-mail: leonardofvribeiro@gmail.com. Orcid: https://orcid.org/0000-0002-8879-2916
} 
ABSTRACT: This paper aims to investigate how the cinematic images reverberate in the body, the attempts to define its measurements and its limits on the contact between the film and the viewer promoted by the cinematic experience. The film's ability to touch, emulate the sensations in our body reveals how it is also a perceptive and expressive being, with movement ability and tactility. And from this, look for these body experiences in recent Argentine cinema, with commentaries on the movies Jauja and The Human Surge (El auge del humano).

KEYWORDS: cinema; sensoriality; body; Lisandro Alonso; Eduardo Williams

RESUMEN: Este artículo tiene como objetivo investigar cómo las imágenes cinematográficas reverberan en el cuerpo, los intentos de definir sus medidas y sus límites en el contacto entre la película y el espectador promovido por la experiencia cinematográfica. La capacidad de la película para tocar, emular las sensaciones en nuestro cuerpo revela cómo también es un ser perceptivo y expresivo, con capacidad de movimiento y tacto. $\mathrm{Y}$ a partir de esto, busque estas experiencias corporales en el cine argentino reciente, con comentarios sobre las películas Jauja y El auge del humano.

PALABRAS CLAVE: cine; sensorialidade; cuerpo; Lisandro Alonso; Eduardo Williams 


\section{Contato fílmico: relações táteis no cinema argentino contemporâneo}

Filme, corpo e reversibilidade

Em geral, as reflexões que fazem as teorias clássicas do cinema não o abordam como um mundo próprio que expressa a vida, uma experiência que emula a experiência vivida. Nem explora a relação mútua entre filme e espectador, com propriedades que atravessam as estruturas corpóreas, por modos de estar no mundo.
[...] 0 ato de ver um filme oferece um imediatismo e uma violência de sensações tamanha que envolve completamente o olhar e o corpo do espectador; ao mesmo tempo, porém, afirma-se uma desmaterialização radical das aparências. A imagem cinematográfica é ao mesmo tempo interna e impalpável. Por um lado, o filme [...] é inescapavelmente literal. As imagens confrontam o espectador diretamente, sem mediação. 0 que vemos é 0 que vemos [...]. (SHAVIR0, 2015, p. 37) 
A percepção cinematográfica caminha menos por esses parâmetros representativos e mais nos que são ordenados pelos mecanismos desenvolvidos pelo aparelho cinematográfico, como aponta Shaviro. A imagem possui uma instabilidade no seu estar no mundo e sua carnalidade está no afeto, nas sensações. O que foi feito para elas existirem não importa mais do que elas próprias existindo. O que parece diminuir seu poder é a aparente escassez de fisicalidade, de substância, impedidas de exprimir algo além de elas mesmas, associando-as, portanto, a coisas vazias e impotentes. Mas o poder das imagens habita em sua capacidade de afetar o espectador, de fazer emergir sensações às quais o corpo responde muitas vezes de maneira cinética.

Shaviro afirma que os filmes não apresentam objetos, apenas os projetam. Essa essência estaria na crueza e na subjetividade da percepção e, visto isso, pôr a percepção sob a lente de uma consciência mais reflexiva ou julgamento seria mais difícil analisá-la, uma vez que se distanciaria de sua essência. Sem as formas e contextos, as imagens do filme são conteúdos brutos de sensação, de expressão. Examinando-as dessa maneira se chegaria a um novo tipo de percepção; uma percepção múltipla e não hierárquica, nem intencional. Nesse lugar, não se está mais subordinado às exigências da representação, reconhecimento, idealização ou campos teóricos distintos do cinema que the preparam um molde prévio e parcial de análise.

O envolvimento do espectador com a imagem é, em primeiro lugar, intenso no estímulo direto dos nervos óticos, desvinculado dos conhecimentos cognitivos e reflexivos. A própria agitação dos sentidos e seu fascínio não poderiam ser reduzidas pelo amortecimento dos conceitos ideológicos ou imaginários. A experiência cinematográfica rompe com isso e reivindica uma percepção mais sensível.

\section{0 cinema me convida, ou me força, a permanecer na órbita dos sentidos. Sou confrontado e agredido por um fluxo de sensações que não posso relacio- nar a uma presença física nem traduzir em uma abstração sistemática. Eu sou violenta e visceral- mente afetado por essa imagem e esse som, sem contar com o recurso de algum tipo de referência, de alguma reflexão transcendental, ou de uma or- dem simbólica. Uma estrutura significante não po- de mais antecipar todas as percepções possíveis: em vez disso, a contínua metamorfose da sensação}


se apropria, se esgueira e ameaça desalojar todo 0 conforto e a estabilidade do sentido. (SHAVIRO,

2015, p. 45)

O corpo seria capaz de efetivar uma relação reversa e comutativa de sentimentos subjetivos e conhecimentos objetivos; promover uma relação entre os sentidos e o seu próprio tema, onde não há uma divisão clara e definitiva, mas "uma continuidade entre as respostas fisiológicas e afetivas do meu corpo e as aparências e desaparecimentos dos corpos e imagens da tela". (SHAVIRO apud SOBCHACK, 2004, p. 61)

Essa reversibilidade entre expressão e percepção não é sintetizada por um pensamento único nem definitivo, sequer é separada da consciência. Esta, inclusive, que é vinculadora dessa relação de incorporação mútua, como um "espaço único que separa e reúne, que sustenta cada coesão" (MERLEAUPONTY apud SOBCHACK, 1992, p. 4), isto é, o mundo experienciado e o corpo vivido.

Sobchack acredita que a percepção corporal é um pilar da comunicação da experiência cinematográfica, que implica em aspectos da visão, da audição e dos movimentos da experiência sensível, estes que são traduzi- dos em um sentido sensível que resultam em um sentido visível e audível.

\section{Em sua presença e atividade de percepção e ex- pressão, o filme transcende 0 cineasta a constituir e localizar seu próprio lugar, sua própria experiência perceptiva e expressiva de ser e se tornar. (SOBCHACK, 1992, p. 9, tradução minha)}

O espectador está nessa teia, com suas estruturas expressivas e perceptivas, significando e experienciando o filme. A experiência cinematográfica expõe o espaço habitado pela experiência direta, tornada acessível e visível pelas condições de "encorporação"1 que envolvem o espectador. No espaço habitado, o espectador está, em menor ou maior grau, em um nível de consciência dessa natureza dupla e reversível da percepção cinematográfica, de sua expressão como um processo de percepção.

Quando Sobchack afirma que tocamos o filme é porque nossos sentidos entram em contato com a estrutura e a dinâmica concebida no filme e porque também somos tocados por suas informações, gradações de luzes, noções de percepção e espaço. O toque é "real e contínuo, uma questão do circuito de vibrações 
sensoriais que liga o espectador à tela". (EISENSTEIN apud SOBCHACK, 2004, p. 55)

O corpo e a representação cinematográfica não refletem um ao outro. Eles estão a todo momento se informando em uma relação não hierárquica, mas de choques de afetos. É uma situação reversível e incomensurável em níveis representativos, que se manifesta por meio de uma experiência oscilante, ambivalente e frequentemente ambígua.

\section{Uma visão tátil}

Um passo adiante dessa discussão seria entender essa relação entre corpo do filme e do espectador de uma maneira mais próxima. O próprio uso da palavra toque não é ordinário. A imagem audiovisual pode fazer emergir nos sentidos do espectador uma lembrança tátil, revelando uma capacidade de toque que a visão revela, como se no lugar de ver as imagens à distância, os olhos conseguissem deslizar, esfregar, acariciar.

Laura Marks (2000) investiga esse fenômeno cinemático se baseando em como o cinema pode resgatar da memória do espectador uma sensação de toque quando em contato com a imagem cinematográfica. 0 cinema, para Marks, apela ao contato incorporado com o objetivo de recriar memórias sensórias no espectador. A força intangível e histórica dos objetos, dos corpos pode ser traduzida pelo cinema a partir de experiências que evocam outros sentidos além da visão.

A visão que Marks defende está menos ligada à atividade cognitiva e mais a uma visão que, de alguma maneira, se entrega à imagem, que não se propõe a uma relação de dominação para com a imagem. Nessa modalidade, o contato entre os corpos é mais próximo, muito parecido com o contato entre corpo do filme e do espectador explicado por Sobchack e Barker. E para que isso ocorra, para que nosso corpo funcione como sistema de percepção, para que se entregue à imagem e a penetre, é preciso que estejamos minimamente desconectados das funcionalidades do nosso copo, dos nossos sentidos. Marks explica:

\section{Um certo grau de separação do corpo é necessário para que nossos corpos funcionem. Imagine se nos- sas percepções estivessem tão incorporadas que pu- déssemos sentir cada passo de nosso processo diges- tivo, a contração de nossos neurônios. Estaríamos tão sintonizados com o universo que seria impossível}


nos concentrarmos no mundo ao nosso redor. Se estivéssemos cientes do funcionamento dos nossos baços, da constante atividade sobre as membranas mucosas de nossas narinas, do tráfego em nossas estradas sinápticas, certamente não seríamos capazes de dirigir um carro, quanto mais distinguir as percepções mais necessárias para a sobrevivência. (MARKS, 2000, p. 132, tradução minha)

Aqui, poderíamos fazer um paralelo com a memória sinestésica de Barker (2009), em que os movimentos do filme, neste caso, suas propriedades táteis, nos lembraria uma sensação de nossa história e, com isso, nos colocaria mais próximos à sensação que o filme objetiva emanar em nossos corpos. Há, portanto, uma relação mimética entre esses corpos: a imagem cinematográfica elabora uma forma de representação baseada em um contato material com o espectador. O que ocorre é um parentesco indicioso com a imagem, não diretamente com o que é representado, mas principalmente com seu efeito sensório. Esse contato físico com a imagem se dá quando o que passa na tela atravessa o sistema sensório do espectador, fazendo-o entender com a força do seu corpo, e não tanto com sua capacidade cognitiva.
Marks (2000) recorre a Bergson para afirmar que uma imagem é multissensorial, isto é, que vai além da visão, inferindo sobre todos os sentidos que percebem um objeto. E é na superfície do corpo (na pele, na tela) que a sensação e a percepção coincidem, invocando uma mediação da memória. O esquema dessa trajetória seria: primeiro nos movemos para o objeto na tela, depois recordamos imagens virtuais que nos vêm à memória e as comparamos com o que está na tela. Isso é compatível com o modelo de percepção de Bergson, que é referência para Deleuze e sua imagem-tempo.

No exercício de transitar pelo tempo na imagem, nossos olhos percorrem aquela superfície como órgãos de toque, deslizando de canto a canto da imagem, em uma experiência sensória de assimilação narrativa. Enquanto percorremos sobre a pele, a superfície do filme, o filme também nos percorre, caminhando por nossos sentidos e deixando seus rastros afetivos, suas marcas em nosso corpo.

Elucidando as maneiras que o cinema evoca o sentido do tato, Marks desenvolve o conceito de visualidade háptica, em que o olhar se move sobre a superfície da imagem, da 
tela, do objeto, mais preocupado em investigar a textura do que codificar a forma. $O$ olhar aqui é incentivado a flanar pela imagem e não a se concentrar em um único ponto.

Tais imagens oferecem tal proliferação de figuras que 0 espectador percebe a textura tanto quanto os objetos imaginados. Enquanto a percepção óptica privilegia o poder representacional da imagem, a percepção háptica privilegia a presença material da imagem. A partir de outras formas de experiência sensorial, principalmente toque e cinestesia, a visualidade háptica envolve o corpo mais do que no caso da visualidade óptica. 0 toque é um sentido localizado na superfície do corpo: pensar no cinema como háptico é apenas um passo em direção a considerar as maneiras como 0 cinema atrai o corpo como um todo. (MARKS, 2000, p. 163, tradução minha)

Em Jauja (2014), quinto longa-metragem do argentino Lisandro Alonso, as imagens não nos territorializam em um lugar, mas em sensações. Sentimos a textura do solo de maneira ávida, o deserto e sua pastagem, o mar, tudo parece vir à superfície da tela, disponíveis à aproximação física do nosso corpo (Fig. 1 e 2). A imagem foge da representação para ser matéria. Matéria bruta pa- ra sensações, sentimentos que traduzem uma maneira de viver naquele universo.

No lugar de nos fixar na narrativa, a imagem háptica nos fixa na matéria, fazendonos contemplá-la. Aqui, é possível uma materialização do afeto, uma vez que empreendemos uma contemplação incisiva sobre o espaço fílmico. Para conseguir esse caráter háptico, filmes empreendem combinações técnicas como granulação e desfoque da imagem, como um close-up muito próximo do objeto a pronto de desfigurá-lo, talvez até em busca se seu átomo. As imagens hápticas desestimulam o espectador a pensar sobre uma representação e o coloca em uma relação incorporada e multissensorial com o filme.

A visão do espectador tem uma relação tátil com a superfície da imagem, movendo-se sobre as figuras que se fundem no plano da imagem, como se as coisas até mesmo distantes estivessem a apenas um centímetro do corpo da pessoa. Olhar de tal maneira requer do espectador uma certa confiança, que os objetos da visão não são ameaçadores, mas esperarão pacientemente para serem vistos. (MARKS, 2000, p. 181, tradução minha) 

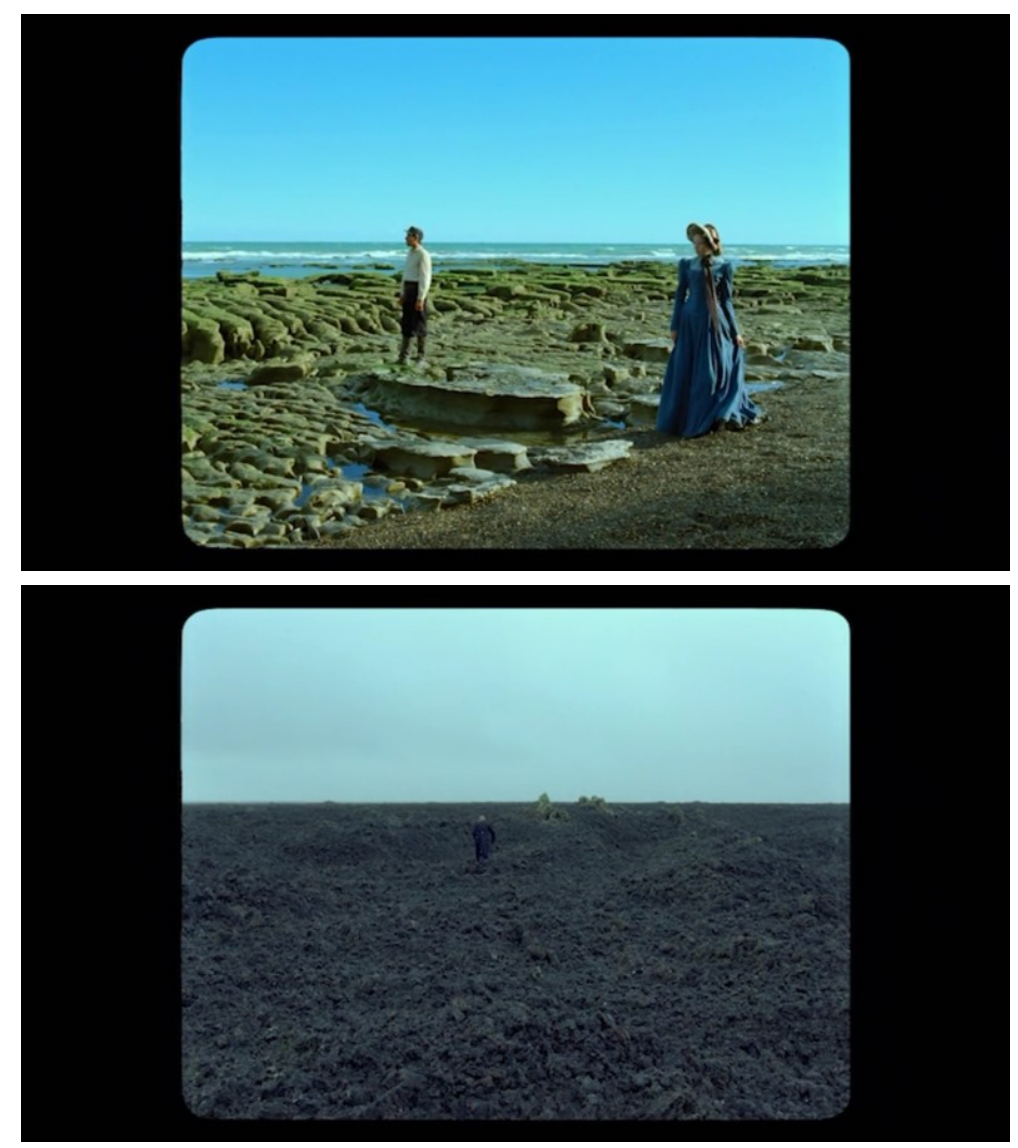

Fig. 1 e 2 - Frames do longa-metragem Jauja (2014), do cineasta argentino Lisandro Alonso 
A pele de Jauja é interessante porque é extremamente tátil, como carne, no entanto, se situa nos limites de uma película. O filme não esconde seu corpo tecnológico, evidenciando sua forma física, onde o caráter midiatizado é bem destacado. A tela e seus limites bem demarcados se posicionam de maneira que parece que estamos entrando em um universo desconhecido e o explorando por uma espécie de fresta. As superfícies se metamorfoseiam em estados de matéria e a experimentamos de perto e em segredo.

\section{Ressonância carnal e um novo toque}

No entrelaçamento entre filme e espectador, na experiência cinematográfica, há momentos em que o que se sente no corpo do filme e no do espectador é o mesmo, em níveis de intensidade, ritmo e proximidade. No instante em que parece que excedi os limites do meu corpo, percebo que o que propiciou isso foram as imagens e meu próprio corpo, visto as intensidades afetivas que transpassam pelos corpos e minha capacidade fisiológica de senti-las.

Nos planos longos de El auge del humano (2011), de Eduardo Williams, a câmera segue trepidante e constantemente o protagonista e por vezes podemos sentir a inci- dência dos pés. Mais que flutuar, o filme caminha pelos espaços. No meio do fluxo, o protagonista desce as escadas e o movimento que a câmera faz é o mesmo, sua percepção chacoalha no ritmo de um descer de escadas. Como já estamos imersos nesse fluxo, fica latente a sensação de que quem caminha também somos nós.

Sobre esses momentos, Paasonen desenvolveu estudos focando o caso da pornografia on-line e toda sua estrutura midiática, calcada na materialidade em que essas relações de contato se configuram. Seu foco em pornografia é um passo a mais das teorias sensórias do audiovisual, uma vez que seu olhar está aberto para as transferências corpóreas que ocorrem na visualização dessas obras, e essas transferências, ela afirma, envolvem um complexo de carne, convenções genéricas, tecnologias, bem como fatores materiais, imateriais, humanos e não humanos (2011).

Nos momentos que me referi anteriormente, a teórica desenvolve o conceito de "ressonância carnal". (PAASONEN, 2011) Aqui, o espectador é visto como fonte e ponte de ressonâncias. 
Frequentemente, as frequências corretas e as "vibrações simpáticas" são descobertas por acaso, já que certas imagens entre centenas e milhares de pessoas grudam, atraem a atenção, fascinam e estimulam futuras revisitações. Em contraste, outras ressonâncias são experimentadas como perturbadoras e desagradáveis, como tipos revoltantes de dissonância, como choques pontiagudos, ou como envolvendo uma série de respostas confusas sendo surpreendidos, assustados, entediados, divertidos, envergonhados, confusos e excitado. (PAASONEN, 2011, p. 16, tradução minha)

A ressonância é carnal devido às sensações e vibrações que ela causa no corpo espectador que podem ser difíceis de traduzir. $O$ estudo de Paasonen considera as contribuições de Marks, Sobchack e mais uma gama de teóricos do sensório que se debruçam sobre a carne humana, a textura das imagens. Dessa maneira, ela também observa as mediações materiais que possibilitam o engajamento corpóreo da pornografia online, toda tecnologia que inclui cabos, modems, hardware.

No centro dessa interação está a presença física e acessibilidade visual de seus intérpretes, facilitada pela comunicação em rede e apoiada pelas noções de realidade e autenticidade associadas às tecno- logias de inscrição, geração de imagens, gravação e transmissão (via fotografia, vídeo e Internet). Tal

"resíduo carnal" é crucial para os registros afetivos, força e apelo do pornô online. (PAASONEN, 2011, p. 17, tradução minha)

A ressonância carnal cria laços com a experiência incorporada que investigo pelo seu parentesco em questão afetiva e midiatizada, como podemos ver. O que ela atenta em um grau maior seria o modo digital em que essa experiência se desenvolve, o que a aproxima do cotidiano midiatizado em El auge del humano. Em uma cena, um grupo de rapazes se exibe pela webcam por dinheiro. Assistimos a todo o momento através de um plano desinteressado, que os filma como uma câmera de vigilância. Por outro lado, o som das práticas sexuais é bem palpável, próximos desse contato íntimo com o espectador que Paasonen ensina. Os próprios corpos nus se misturando à imagem granulada denotam uma sensação de textura, de verossimilhança.

A experiência de uma webcam é muito importante nessa questão. Elas insinuam um real, um autêntico nas imagens, sua mediação é mínima porque ela precisa "desaparecer" para que a ressonância carnal se mani- 
feste. Elas são simplesmente "janelas nas vidas íntimas das pessoas". (PAASONEN, 2011, tradução minha) Os rapazes da cena estão nus em um quarto, se esfregam, se chupam em um show de intimidade midiatizada. Essa troca íntima com a pessoa do outro lado do computador faz emergir uma sensação de conectividade e presença, facilitada pelas tecnologias de rede.

Em outra cena de exibição sexual por webcam, somos iniciados pela perspectiva do espectador que está do outro lado do site, pois vemos o computador e as outras páginas de web que ele visita simultaneamente. Logo a tela do computador toma toda a imagem cinematográfica, intensificando uma experiência de espectador daquele show. Quando tudo termina, eles se vestem e vão para a rua. O que ocorre é uma transição de webcam para câmera extradiegética que tem nos guiado pelos fluxos do filme. Somos transportados para outra parte do mundo por dentro de uma webcam. A superfície da imagem da webcam toca a tela, em uma conexão que se nota depois de sua manifestação.

[...] imagens em tempo real como aquelas fornecidas por webcams atualizam-se e apontam para ou- tro lugar: "elas fazem nossas redes parecerem transparentes e, assim, cumprem a promessa das redes de fibra ótica para nos conectar. para o mundo, assim como cotações de ações em tempo real e banners de notícias" (CHUN apud PAASONEN). [...] Imagens de webcam são experientes como traços "de um ser humano real que está sendo localizado em outro lugar" - isto é, como signos indiciais de presença, enquanto a interação entre os operadores de câmera e seus públicos envolve o desejo de "alguém tão perto e ainda tão longe, porque apenas fora do material alcance". (HILLIS apud PAASONEN, 2011, p. 76, tradução minha)

Essa transparência referida por Paasonen explica como é possível uma aproximação tátil entre os corpos que se comunicam por essas pequenas câmeras. Podemos ver traços corpóreos muito próximos da tela em uma proximidade visual com indícios de presença e contato, sem esquecer que também há um distanciamento. A textura da imagem, combinada com o som, torna acessível uma materialidade disponível para a percepção sensória.

$\mathrm{Na}$ cena em que o protagonista urina em um formigueiro, a câmera segue o derradeiro caminho da urina em direção ao formigueiro e vai lentamente penetrando-o

Leonardo Ribeiro, Contato fílmico: relações táteis no cinema argentino contemporâneo. 
(Fig. 3 e 4). A sensação tátil não poderia ser maior. A câmera vaga por dentro dos orifícios e entre as formigas, agora gigantes, e somos levados a flanar por esse espaço, construindo todo nosso contato próximo com imagens imprecisas e volumosas, como se nossos olhos pudessem tocá-las. O fluxo agora é majoritariamente material.

Não se explica nada racionalmente, em uma trajetória tátil por um universo. E depois saímos do formigueiro também tatilmente, com a textura da terra por toda a tela até chegarmos em uma mão em plano fechado, onde a geografia da pele é explícita. A mão, por sua vez, começa a digitar no celular, ligando nossa perceção ao touch screen do celular. Paasonen chama atenção para as propriedades materiais específicas das imagens digitais. Seu aparato de mediação (hardware, cabos e fios) estão inesperáveis das maneiras como essas imagens são experimentadas. (PAASONEN, 2011)

$\mathrm{Na}$ cena em que experimentamos o olhar do espectador de webcam em El auge del humano, é preciso repetir, o personagem assiste a um show na webcam, mas também navega por outros sites. A superfície da tela do computador vem à tona em ca- madas, em busca de uma profundidade do digital. Há mais de um acontecimento na mesma superfície e vê-se o tempo passar por essa experiência que não foca primeiramente no que passa da imagem, mas sim na imagem em si. Seria possível um encontro de duas imagens-tempo?

Ao fim do filme, em uma fábrica, vê-se um grupo de trabalhadores enfileirados manuseando o que depois o filme nos mostra em perfeitas definições. Um equipamento com seu interior exposto, tendo suas estruturas manipuladas com ferramentas. A cena se estende e é possível caminhar com os olhos por toda a extensão do aparelho (Fig. 5).

Diante dessa materialidade escancarada, lembro-me das análises que Shaviro e tantos outros teóricos do sensório no cinema fazem sobre a obra de Cronenberg. Shaviro destaca a insistência de Cronenberg na tecnologia da carne, fazendo dela o espaço principal das transformações e choques sociais, em sua materialidade crua. Nos filmes do diretor, a tecnologia reforça nossas experiências corpóreas, testando limites desconhecidos. Shaviro explica: 


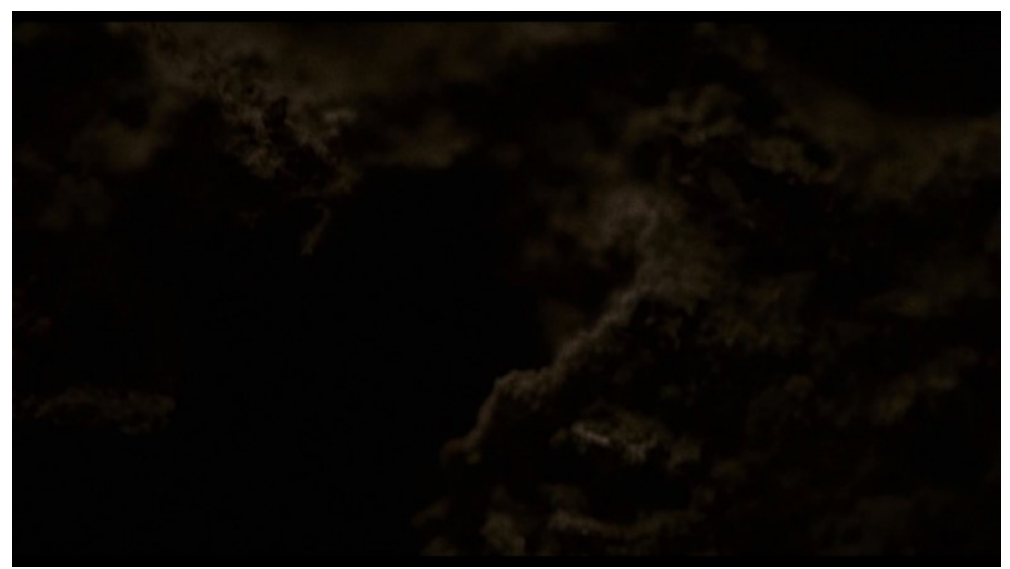

Fig. 3 e 4 - Frames de El auge del humano (2011), de Eduardo Williams

Leonardo Ribeiro, Contato fímico: relações táteis no cinema argentino contemporâneo. 


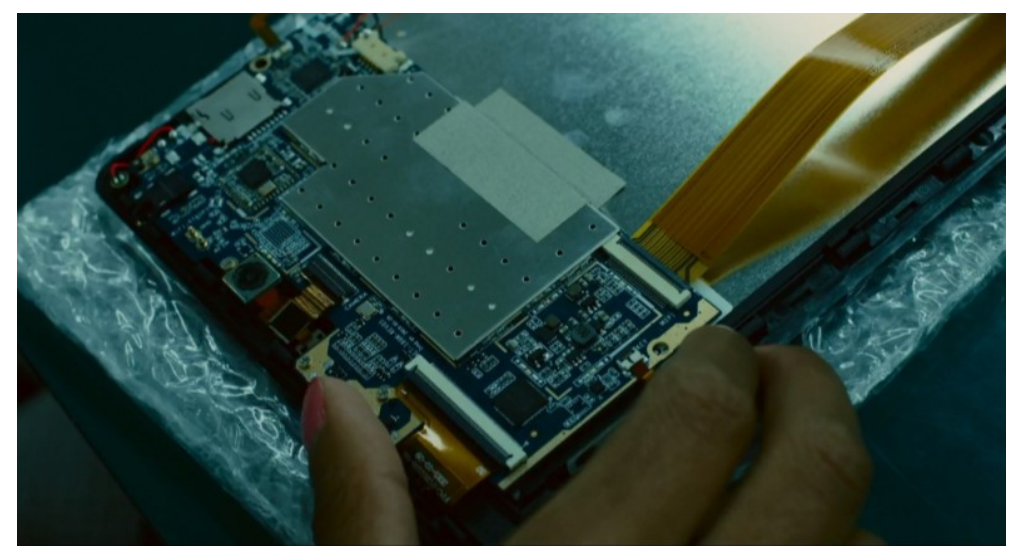

Fig. 5 - Frame de El auge del humano (2011), de Eduardo Williams 
Cronenberg é um literalista do corpo. Tudo em seus filmes é corporal, baseado na interseção monstruosa entre fisiologia e tecnologia. Afecções corpóreas não são sintomas psicanalíticos a serem decifrados; eles, de fato, são, por si só, movimentos de paixão. 0 corpo é o lugar das mais violentas alterações e das mais intensas afecções. [...] Novos arranjos de carne destroem as oposições tradicionais binárias entre mente e matéria, imagem e objeto, self e outro, dentro e fora, masculino e feminino, natureza e cultura, humano e inumano, orgânico e mecânico. De fato, a desmontagem sistemática de tais distinções, em todos os níveis possíveis, é o maior princípio estrutural de todos os filmes de Cronenberg.

Crio relações da lógica da carne em Cronenberg com a imagem do aparelho com seu interior exposto em El auge del humano. Suas pequenas partículas são como as terminações nervosas do meu corpo. Percebo um corpo aberto e dissecado na minha frente, manifestando as entranhas do digital.

Percebo uma tatilidade difícil de descrever, mas que já consigo reconhecer indícios em minha pele. Suspeito o que poderia ser uma nova memória sensória, própria da contemporaneidade, propiciada pelo capitalismo tardio. A sensação de toque no touch screen e uma tatilidade digital me parecem se referir ao corpo que está transitando entre o fisiológico e o digital, o que me inspira a experimentar essa superfície, a entrar em contato com esse corpo digital e provar de novas capacidades sensórias. Isso me deixa curioso para conhecer essa nova experiência, a qual possibilita ao cinema novas estratégias estéticas de emular um novo estar no mundo e traduzir o que o corpo pode nos dizer.

\section{Notas}

${ }^{1}$ Tradução livre do termo embodiment, sem equivalente em português, que descreve a relação entre filme e espectador, onde a linguagem de reversibilidade entre percepção e expressão são enraizadas, em que a existência simultânea dos dois corpos não interage de maneira dialética, sem um corpo que dê a última palavra.

Leonardo Ribeiro, Contato fílmico: relações táteis no cinema argentino contemporâneo. 


\section{Referências}

BARKER, Jennifer. The Tactile Eye: Touch and the Cinematic Experience. Berkeley; Los Angeles; Londres: University of California Press, 2009.

MARKS, Laura U. The Skin of the Film: Intercultural Cinema, Embodiment, and the Senses. Durham, NC: Duke University Press, 2000.

PAASONEN, Susanna. Carnal Resonance:

Affect and Online Pornography. Cambridge: MIT Press, 2011.

SHAVIRO, Steven. O corpo cinemático. São Paulo: Paulus, 2015.

SOBCHACK, Vivian. The Address of the Eye: Phenomenology and Film Experience.

Princeton: Princeton University Press, 1992.

SOBCHACK, Vivian. Carnal Thoughts: Embodiment and Moving Image Culture.

Berkeley: University of California Press, 2004. 